\title{
The renaissance of barrier methods
}

\author{
Lindsay Edouard
}

International Advisory Editor, Port Louis, Mauritius

\section{Correspondence to}

Professor Lindsay Edouard; soranae@gmail.com

Received 26 January 2012 Accepted 9 February 2012

\section{Summary}

In 1987, the threat of litigation led to the withdrawal of intrauterine devices (IUDs) from the American market where depot medroxyprogesterone acetate (DMPA) had already been banned. There were fears of repercussions that would have led to the limiting of contraceptive choice in Britain. HIV was also an emerging issue and a revival of interest in barrier contraception led to an emphasis on male condoms, with strengthening of manufacturing standards, promotion in the media, improved accessibility and emphasis of their value for dual protection. Twentyfive years later, links still need to be sought within reproductive health services, especially at the interface between the management of contraception and opportunities for HIV prevention.

\section{Restricting choice}

An editorial in this Journal in $1987^{1}$ referred to 'The customer comes first' as a current political slogan and stressed the role of choice when "the commodity on offer is contraception". It was felt that there was a threat that "freedom of choice will be whittled away", as two government discussion documents had neglected to mention community services for family planning despite their widespread recognition as being essential for primary health care. ${ }^{2}$ Community services were perceived as providing value for money, as well as offering alternatives both to hospitals as service delivery points and to general practitioners (GPs) for service provision. It was felt that GPs tended to focus on oral contraception, to the exclusion of IUDs and barrier methods.

At that time, major challenges were being faced in the promotion of IUDs, both because of inadequate service provision and due to misconceptions regarding their indications, contraindications and effectiveness. Whereas IUD fitting by hospital gynaecologists would provide "a contraceptive service nearer to the Rolls-Royce than the rickshaw" for the great benefit of a few individual clients, it seemed more appropriate for service improvement to prioritise the training of community-based staff. IUDs had received poor publicity due to the erroneous attribution of adverse effects, such as pelvic infections, to the devices themselves as opposed to their surrounding clinical circumstances. With these incorrect views also prevailing in courts of justice in the USA, manufacturers could not afford the insurance premiums to enable them to defend themselves against litigation. All IUDs, except for the Progestasert ${ }^{\circledR}$, had been withdrawn from the North American market. ${ }^{4}$ Transatlantic repercussions ensued with the withdrawal of the most popular IUD, the Copper 7, from the British market by its multinational pharmaceutical distributor. ${ }^{5}$ It was most unfortunate that commercial interests, and not clinical considerations, now limited choice in the selection of a contraceptive method. The USA was described as "a society devoted to the restriction of contraception" and with the important role of that country as an international donor for family planning, there were potential global implications as had previously been experienced with their ban on DMPA. ${ }^{6}$

\section{Emerging contraceptive methods}

A clear distinction was made between contraceptive technology and family planning, which was described as the "art and craft which uses the science of contraception incorporating the sociology of culture". ${ }^{6}$ The management of female infertility, especially the evolution of in vitro fertilisation, had benefited significantly from advances in reproductive physiology that followed research on new contraceptive methods for fertility control in developing countries. However, lack of interest in male contraception had led to underfunding of research in that field, with persistently poor insight into male reproductive physiology and male psychology. With each 'pill scare', male contraception received renewed attention, but available 
methods had not progressed beyond vasectomy and condoms. Whereas the male pill was "clearly a long way off", doubts were expressed regarding its acceptability both to men due to "their self-doubts about their machismo" and to their female partners who would mistrust reliable pill-taking by men, preferring femalecontrolled methods "to keep their own fertility in their own hands". ${ }^{7}$ Sadly, little has changed over the ensuing 25 years.

The newly developed progesterone antagonist, RU486 (mifepristone), was perceived as having potential for effective and convenient contraception in view of its effects in monkey experiments. ${ }^{8}$ The Today ${ }^{\circledR}$ vaginal sponge, impregnated with nonoxynol-9, was being used increasingly but "the unpleasant taste of the sponge prohibited oral sex". ${ }^{9}$ A new arcing spring diaphragm, with diameters ranging from 60 to $95 \mathrm{~mm}$, was considered to be useful by the Clinical and Scientific Advisory Committee of the National Association of Family Planning Doctors (NAFPD) ${ }^{10}$ and there was much interest in the role of spermicidals ${ }^{8}$ to improve the effectiveness of female barrier methods. With emerging developments in materials technology, it was suggested that disposable diaphragms could be produced that were affordable and that would be of the correct size for the individual woman. ${ }^{11}$ As will be seen later in this article, that contributor to the Journal was remarkably prescient and, 25 years on, a product fulfilling most of her criteria will become available in the near future.

\section{Increasing HIV prevention}

With the emerging HIV epidemic, guidelines issued jointly by the Family Planning Association (FPA) and NAFPD stressed that "family planning and well woman services will have an important role in preventing the spread of HIV". Among other issues, the guidelines addressed health education, counselling, condom distribution, infection control in clinics, screening and confidentiality. ${ }^{12}$ As condoms had come to the fore, it was anticipated that a multitude of brands would invade the market, and as a result confusion was feared. The Journal reported that a letter had been sent from the FPA to the British Standards Institution, urging the introduction of "an appropriate standard for condoms as far as the spread of HIV virus is concerned". ${ }^{13}$ With cost sometimes being an obstacle for men to use condoms,${ }^{14}$ it was apt for a notice at the Margaret Pyke Centre in London to state that "Sheaths will be supplied on request free of charge for additional protection, whatever your method of contraception". ${ }^{15}$ Advice regarding dual protection had already become the norm in the delivery of contraceptive services.

However, it was recognised that conventional messages for HIV prevention were "negative, antifun, dull if not totally unreasonable". ${ }^{15}$ The HIV threat led to greater openness in discussion of sexual activities, thereby promoting psychosocial research for policy formulation for communication encouraging behaviour change. ${ }^{16}$ Materials for both teachers and pupils quickly became available for health education on AIDS in the classroom ${ }^{13}$ and there was a massive "no holds barred" campaign on British television with explicit details that included a demonstration of putting on a condom. ${ }^{17}$

\section{Addressing concerns}

Some 25 years on, with the success of antiretroviral therapy in prolonging life, HIV-positive individuals now feature prominently in the reproductive age group in most parts of the world, with increasing relevance for the need for links between contraception and HIV prevention within reproductive health services. As a result, it has been advised that reproductive health practitioners should become familiar with HIV drug regimens. ${ }^{18}$ It is often forgotten that contraception is a very important measure for the prevention of mother-to-child transmission of HIV.

The utilisation of a wide range of contraceptive methods is regarded as highly desirable in order to meet the perceptions and preferences of individuals. Fortunately, IUDs survived the crisis of the mid1980s through reassurance regarding their safety in an authoritative and comprehensive report that was issued promptly by the World Health Organization (WHO), ${ }^{19}$ thereby demonstrating that great benefits could be gained by international collaboration. Activities to encourage the uptake of services have been emphasised in international, multilateral family planning programmes. But with the interest of donors in achieving short-term tangible results, resource allocation has tended to favour funding for service delivery, to the detriment of contraceptive research and development aimed at the introduction of new methods. Biomedical research is crucial. Paragraphs 12.10 and 12.12 of the Programme of Action of the International Conference on Population and Development in 1994 specified that increased support was needed "to bring a number of potential new, safe and affordable methods to fruition, especially barrier methods" for both "fertility control and the prevention of sexually transmitted diseases, including HIV/AIDS, as well as microbicides and virucides, which may or may not prevent pregnancy". ${ }^{20}$

In the quest for alternative female-controlled barrier methods to complement the female condom in the range of options, activities in research and development have focused on cervical barriers, allowing discreet use and avoiding interference with spontaneity. The SILCS diaphragm, a contoured singlesize silicone device, is comfortable, easy to use, and does not require a pelvic examination for fitting, a major advantage in low-resource settings. ${ }^{21}$ Apart from the fact that it is not disposable, it fulfils the hopes expressed in this Journal 25 years ago. ${ }^{11}$ Its 
commercial production is likely to commence soon, once regulatory approval is obtained. The potential of the SILCS diaphragm as a microbicide delivery system is currently being investigated. ${ }^{22}$

The safety of hormonal contraceptive methods has recently been questioned again, the controversy now relating to the possibly increased risk of HIV acquisition, progression and transmission. ${ }^{23}$ The level of risk varies substantially between population groups, as exemplified by the general population in low HIV prevalence environments, as opposed to specific groups in high-risk settings. Clinical judgment will need to be exercised: a small increase in the risk of HIV might yet be acceptable in view of the high contraceptive efficacy of hormonal methods. As hormonal contraception is known not to protect against HIV, a barrier method should be used concurrently - advice that was already being given 25 years ago. ${ }^{15}$ The conflicting results from observational studies on the risk of HIV may possibly be due to methodological problems. While awaiting the conclusions of further studies that will take years, there are even more reasons for the intensified promotion of the concurrent use of barrier methods, especially male condoms, which, as confirmed by the recent WHO statement, ${ }^{23}$ remain the mainstay of dual protection.

\section{Competing interests None.}

Provenance and peer review Commissioned; internally peer reviewed.

\author{
References \\ 1 Editorial. A loss of choices. Br J Fam Plann 1987;13:39. \\ 2 Anonymous. Response to the DHSS discussion documents. \\ Br J Fam Plann 1987;13:25-27. \\ 3 Siddle N. IUDs - a change of approach. Br J Fam Plann \\ 1987;12:138-142. \\ 4 Smith S. A crisis for the coil. Br J Fam Plann 1987;12:115-116.
}

5 Anonymous. FPA and NAFPD regret cut in IUDs. Br J Fam Plann 1987;12:143.

6 Walton SM. Contraception USA. Br J Fam Plann 1987;13:71-73.

7 Jeffcoate S. Why no progress in male contraception? Br J Fam Plann 1987;12(Suppl. 4):15-17.

8 Anonymous. From the journals. Br J Fam Plann 1987;13:31-32.

9 Curtis M. TODAY sponge. Br J Fam Plann 1987;12:130.

10 Anonymous. New products. Br J Fam Plann 1987;13:28.

11 Hopwood J. Disposable diaphragms? Br J Fam Plann 1987;13:33.

12 Mills A, Biddell S. AIDS (acquired immune deficiency syndrome), family planning and well woman services. Br J Fam Plann 1987;13:11-15.

13 Anonymous. News and views. Br J Fam Plann 1987;13:81.

14 Elton P, Blair A. A contraceptive service for men. Br J Fam Plann 1987;13:10-11.

15 Guillebaud J. Cervical cancer and courtship. Br J Fam Plann 1987;13:106.

16 Ford N. Research into heterosexual behaviour with implications for the spread of AIDS. Br J Fam Plann 1987;13:50-54.

17 Goodchild R. The condom on television - a missed opportunity. Br J Fam Plann 1987;13:69-70.

18 Shah K. ALIAS (a landing in an alphabet soup). BMJ 2005;331:1071.

19 World Health Organization. Mechanism of Action, Safety and Efficacy of Intrauterine Devices. Report of a WHO Scientific Group (Technical Report Series No. 753). Geneva, Switzerland: World Health Organization, 1987;67-71.

20 United Nations. Technology, Research and Development. Chapter XII. Programme of Action adopted at the International Conference on Population and Development, Cairo, 5-13 September 1994. Paragraphs 12.10 and 12.12. New York, NY: United Nations, 1994.

21 Anonymous. New data emerges on one-size diaphragm. Contraceptive Technology Update 2011;32:139-140.

22. Frezieres RG, Walsh T, Kilbourne-Brook M, et al. Couples' acceptability of the SILCS diaphragm for microbicide delivery. Contraception 2012;85:99-107.

23 Department of Reproductive Health and Research. Hormonal Contraception and HIV (Document WHO/RHR/12.08). Geneva, Switzerland: World Health Organization, 2012. 